\title{
¿CÓMO FUE POSIBLE LA GERMINACIÓN DE LA FILOSOFÍA EN AL-ANDALUS?
}

\author{
Andrés MARTÍNEZ LORCA \\ Departamento de Filosofia. UNED
}

Los cauces a través de los cuales penetró la cultura oriental en la España musulmana han sido reconstruidos con notable acierto por la historiografía contemporánea. Sirva de ejemplo el valioso estudio del erudito egipcio Mahmud 'Alī Makkīi. Asimismo, nos son conocidas desde hace tiempo las vías de penetración de la filosofía en al-Andalus: las traducciones árabes del griego, los estudios de medicina que distinguirían al pensamiento andalusí por su vena naturalista, y el mu'tazilismo en cuyas argumentaciones teológicas subyace la filosofía griega, especialmente la Lógica.

Pero no se le ha prestado la debida atención a los factores sociales que explican, en última instancia, la aparición y desarrollo del pensamiento filosófico andalusí. Los propios protagonistas de aquel brillante Renacimiento (el primero, en sentido estricto, en suelo europeo) tampoco se preocuparon mucho en desvelárnoslos, probablemente porque, como advirtiera Cornford a propósito de la filosofía griega, los consideraban "supuestos previos" de aquella sociedad que no necesitaban ser aclarados.

Para responder al interrogante de este artículo me centraré, por tanto, no en las causas inmediatas que hicieron posible que fructificara la filosofía en la península de al-Andalus, sino en el subsuelo histórico del que brotó aquella singular contribución a la cultura medieval. Creo, en efecto, que una mejor comprensión de aquel mundo intelectual, todavía poco conocido, exige que investiguemos los cimientos sobre los que se asentaba. Más que analizar los fru-

1 Ensayo sobre las aportaciones orientales en la España musulmana y su influencia en la formación de la cultura hispano-árabe, Madrid, 1968. 
tos del pensamiento andalusí, admirables por su calidad y variedad, me propongo ahora reconstruir las raíces sustentadoras de tan frondoso árbol.

\section{Pluralismo interno de la religión islámica}

La primera y principal raíz es el Islam mismo, y más en particular su núcleo religioso, cuyo espíritu impregna profundamente al conjunto de la civilización árabe-islámica de al-Andalus.

El Islam se presenta como religión integradora de las profecías anteriores. Abraham, Moisés y Jesús son considerados legítimos profetas en el Corán, ya que constituyen etapas previas en el proceso de revelación divina. "Dios ha hecho descender sobre ti, ¡oh, Profeta!, el Libro con la verdad, confirmando lo que le precedía. Hizo descender la Torá y el Evangelio, anteriormente, como guía para los hombres", III, 3-4.

Mahoma continúa, pues, la misión profética iniciada por Abraham, modelo de creyente puro, haniff. "Abraham no era ni judío ni nazareno [cristiano]: era hanify sumiso [musulmán]. Y no formaba parte de los fabricadores de dioses", III, 67/60. (Véase también Corán II, 135/129; XVI, 120-125; y XIX, 4150). W. Montgomery Watt recordó muy oportunamente que «antes de que la palabra musulmán se convirtiera en término técnico, un discípulo de Mahoma se llamaba a sí mismo creyente o hanif $f^{2}$. Un sorprendente eco de esta posición de principio del Islam se encuentra en la carta que el Papa Gregorio VII dirigió al emir de Mauritania, y donde saludaba a éste como "hermano en Abraham" y creyente en el Dios único y creador.

La religión islámica no parte de cero. Por eso, la veracidad del Corán radica en la continuidad de la profecía de Mahoma respecto a los profetas anteriores, como puede leerse en el Credo de los fieles: "Creemos en Dios, en lo que se nos ha hecho descender y en lo que se hizo descender a Abraham, a Ismael, a Isaac, a Jacob y a las doce tribus; creemos en lo que fue dado a Moisés, a Jesús y a los profetas procedente de su Señor: no establecemos diferencias entre ellos, y estamos sometidos a Él», III, 84/78. Véase en sentido similar, IV, 163/161. De ahí la promesa de salvación dirigida a judíos y cristianos en una aleya polémica, pero cuyo significado parece coherente con la línea teológica de

2 Companion to the Qur'än, Londres, 1967, p. 30. 
continuidad profética manifiesta en las páginas del Corán: "Ciertamente, quienes creen, quienes practican el judaísmo, los cristianos y los sabeos, quienes hayan creído en Dios y en el último Día y hagan buenas obras, tendrán la recompensa junto a su Señor. No hay temor por ellos, pues no serán entristecidos", II, 62/59.

¿Qué aportará entonces el Islam respecto a las otras religiones monoteístas? El perfeccionamiento de la profecía anterior. En la perspectiva del mantenimiento de una pluralidad de religiones monoteístas, debe manifestarse según el Corán una leal emulación en el terreno de las buenas obras, horizonte histórico que nada tiene que ver con el fantasma del "fanatismo islámico" con que frecuentemente se denigra al Islam en Occidente. «Hemos hecho descender la Torá, en ella hay guía y luz... Hicimos seguir las huellas de sus profetas a Jesús, hijo de María, confirmando así la Torá que ya tenían. Le dimos el Evangelio: en él hay guía y luz. (...) Hemos hecho descender sobre ti el Libro con la verdad, confirmando los Libros que ya tenían y vigilando por su pureza. (...) Si Dios hubiese querido, ciertamente hubiera hecho de vosotros una sola comunidad, pero os ha dividido con el fin de probaros en lo que os ha dado. ¡Competid en las buenas obras!", V, 44/48, 46/50, y 48/52 y 53.

La plenitud o integridad de la profecía que aporta el Islam significaría lógicamente el punto terminal de aquélla. Por esto, el texto coránico llama a Mahoma "sello de los profetas", hätam al-nabiyyin, XXXIII, 40, expresión que, de una parte, indica la continuidad con los profetas anteriores, y de otra, el cierre o acabamiento del mundo de la profecía. En consecuencia, el Islam no pretendió en modo alguno suprimir la profecía anterior sino perfeccionarla, llevarla a término, completando así "a quienes recibieron una parte del Libro", III, 23/22, subrayado mío. Se mantiene, pues, el mismo núcleo monoteísta común al judaísmo y cristianismo, subrayando la unicidad divina o tawbid, y rechazando de plano todo intento de antropomorfismo religioso y de politeísmo más o menos encubierto.

Pero hay más. El Islam se distingue por un sorprendente pluralismo interno que garantiza un ámbito de libertad para el creyente. "La diferencia de opinión en mi comunidad es un acto de gracia divina", afirma un haditt atribuido al Profeta.

Las diversas sensibilidades religiosas dentro del Islam se encuentran todas en pie de igualdad. "La Ley Sagrada del Islam está expuesta en cuatro versiones, por cuatro escuelas jurídicas [mālikismo, šăfi ismo, hanafismo y zāhirismo], ca- 
da una con sus propios principios, manuales y judicatura. Las cuatro son diferentes; sin embargo, todas son válidas, y viven en tolerancia mutua. (...) Esta doctrina casi parlamentaria de desacuerdo limitado y supuestos básicos comunes, a pesar de períodos de eclipse, sobrevive a todo lo largo de la historia del Islam... Los seguidores de las cuatro escuelas, y de algunas otras que han desaparecido, son todos irreprochablemente ortodoxos. Incluso los šà̄íes, los jariŷ́es y otros, aunque se considera que están en error manifiesto sobre importantes puntos doctrinales y de la Ley Sagrada, siguen siendo musulmanes y disfrutan de los privilegios de tales en este mundo y en el futuro» 3 .

Ya advirtió hace tiempo I. Goldziher sobre la improcedencia de extender el concepto occidental de "herejía" al Islam, pues, a diferencia del cristianismo, no existe en él institución eclesiástica alguna que, mediante concilios y sínodos, fije en precisas fórmulas dogmáticas la norma de ortodoxia. El consenso de la comunidad islámica o $\hat{\imath} \hat{y} m \bar{a}$; supremo criterio religioso, resulta generalmente ineficaz en la práctica dada su elasticidad e inconcreción ${ }^{4}$.

De hecho, es mínimo el núcleo básico del Islam sobre el que hay consenso, la šabáda o profesión de fe: «No hay más Dios que Allāh y Mahoma es su profeta». Una vez aceptada la unicidad de Dios y la profecía de Mahoma, el creyente entra a formar parte de la umma o comunidad islámica; y en ella es libre para adherirse a cualquiera de las escuelas teológicas y jurídicas existentes.

Hasta tal punto el concepto occidental de herejía resultaba extraño al Islam que su homónimo hartaqa es uno de los escasos términos de origen cristiano importados por el árabe literario. Por el contrario, bid 'a o "innovación" expresa un problema de fondo de la religiosidad islámica: el de la licitud/ilicitud de adoptar una doctrina o costumbre que no arranca del Profeta.

A pesar del miedo instintivo de todo espíritu conservador a cualquier innovación por pequeña que sea, el propio desarrollo de la vida social llevó al Islam a una paulatina adaptación al cambiante mundo histórico, dejando a salvo el

3 Bernard LEwIs, "Some observations on the significance of heresy in the history of Islam", en Studia Islamica, I, 1953, p. 54. Trabajo fundamental sobre el tema, que sigo en este punto.

4 Vorlesungen über den Islam, Heidelberg, 1925, 2.a ed., pp. 183 y ss. Cfr. también del mismo I. GoLDzIHER, The Zahiris. Their doctrine and their history. A contribution to the history of islamic theology, Leiden, 1971, pp. 32-34. Por su parte, Félix M. PAREjA (La religiosidad musulmana, Madrid, 1975, pp. 41-42) ha definido al $i \hat{y} m a a^{*}$ como "el sedimento de opinión obtenido durante un dilatado períodon, llegando a compararlo al lento proceso de formación mediante el cual un autor o una obra acaban siendo considerados como "clásicos". 
depósito profético fundamental contenido en el Corán. Por fortuna, un caso especialmente fecundo como el de la zakät ha sido analizado por un estudioso contemporáneo llegando a "descubrir una evolución de las ideas, concerniente a esta institución, bajo el empuje de una transformación política, social y económica» 5 .

Hace más de un siglo, un prestigioso arabista centroeuropeo alertaba contra el prejuicio de considerar al Islam como una realidad al margen de la historia: "así como es imposible negar a priori a la vida social y religiosa del Islam un proceso de continua evolución, así hay que admitir como innegable verdad que también aquí se experimentan continuas mudanzas tanto en cosas grandes como en las pequeñas, en todas partes y en todo" 6 .

Fruto de tal actitud receptiva ante las innovaciones es no sólo la distinción de una bid 'a "buena" (hasana) y una bid 'a "mala" (sayyi'a), es decir, entre una innovación aceptable y otra rechazable desde la perspectiva islámica, sino también el hecho de que, como ha escrito B. Lewis, "la bid'a de hoy podría llegar a ser la sunna de mañana", posibilidad tantas veces confirmada en la historia del Islam, y de la que más adelante veremos algún testimonio concreto a propósito de al-Andalus?.

En resumen, la discrepancia teológico-jurídica está legitimada en el Islam. A diferencia del cristianismo medieval que reprimió las sectas, el Islam medieval las toleró en su seno. El miembro de una secta islámica, aunque criticado por sus desviaciones doctrinales, seguía gozando de todos sus derechos como musulmán. En la umma se integran tanto el creyente común, que sigue el camino tradicional o sunna, como el sectario. Sólo el no-creyente o infiel, káfir (de donde procede nuestro "cafre") quedaba al otro lado de la frontera, y expuesto a severas leyes penales. Por eso, fue tan excepcional en el Islam medieval la acusación abierta de infidelidad, el takfir.

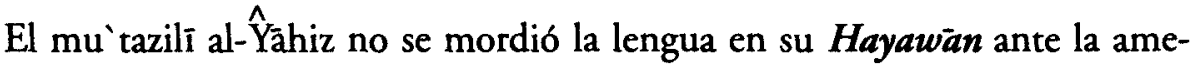
naza potencial procedente de los teólogos: «La piedad de los teólogos consiste

5 Roger ARNALDEZ, "Interpretación económica y social de las teorías de la zakät en el derecho islámico", en Ensayos sobre la filosofia en al-Andalus, Andrés Martínez Lorca, Coordinador, Barcelona, 1990, pp. 266-285.

6 I. GoldziHer, Los árabes españoles y el Islam, Madrid, 1964, p. 20. El texto original procede de una conferencia dada en la Academia de Ciencias de Hungría en noviembre de 1876, y publicada al año siguiente en Budapest.

7 Art. "Bid'a", en Encyclopédie de l'Islam, 2.a ed., tomo I, pp. 1234-1235. 
en apresurarse a denunciar como infieles a los disidentes». Pero, en honor a la verdad, incluso los propios teólogos fueron siempre reacios a formular la acusación de takfir. Veamos algunos ejemplos de semejante cautela.

Según una tradición, el gran teólogo al-Aš arī habría pronunciado estas palabras en su lecho de muerte: "Testifico que no considero como infieles a ninguno de los que rezan hacia la Meca. Todos dirigen sus mentes en la oración hacia el mismo objeto. Sólo se diferencian en la expresión».

Al-Gazzāini, por su parte, en su Kitāb al-faysal entrevió como rayana en la infidelidad precisamente la pretensión de que los teólogos sean tenidos por depositarios de la verdad, y se burló de quienes "convierten el paraíso en el coto vedado de una camarilla de teólogos».

Muy significativa se muestra a este propósito la actitud del teólogo andalusí Ibn Hazm de Córdoba, por ser él mismo infatigable defensor de la ortodoxia islámica desde el literalismo de la escuela zāhirī a la que se adhirió en su madurez. En su magna obra Fisal (tercer tratado, capítulo $6 .^{\circ}$ ) se plantea el problema del takfir. Podemos resumir así su posición al respecto: primero, rechaza a quienes propenden a acusar de infidelidad basándose en ciertos dichos del Profeta, pues tales tradiciones no serían auténticas. En segundo lugar, reconoce los excesos verbales de tantos teólogos, incluido él mismo, en las discusiones dogmáticas: «no hay doctrina alguna teológica que, al ser refutada por el adversario, no sea tachada por éste de infidelidad en el fervor de la disputa». Tercero, propugna una actitud muy tolerante en los casos polémicos, defendida según él por todos los compañeros del Profeta y por destacados juristas: «a ningún musulmán se le debe excomulgar como infiel ni acusar de prevaricador, cualquiera que sea la doctrina dogmática o moral-canónica que profese, pues todo el que, aplicando su esfuerzo mental al libre examen de cualquiera de esos problemas, forma opinión razonada de que tal solución es la verdadera, merece por ello de Dios recompensa en todo caso; si acierta de hecho, la merece doblada, y si yerra, la merece sencillan. Por último, sólo la negación abierta y consciente del texto coránico o el enfrentamiento explícito al consenso unánime de la comunidad islámica le permitirían a Ibn Hazm admitir la acusación de takfirr. "La verdad es que toda persona, de la cual conste de cierto que profesa la religión del Islam, no perderá el título de musulmán, más que en virtud de una razón apodíctica, basada en un texto del Corán o en el consenso unánime de la comunidad islámica que así lo afirmen taxativamente, pero no por meras sospechas o presunciones calumniosas. No debe ser nadie excomulgado como infiel 
por lo que haya dicho, mientras no contradiga con sus palabras algo que a él mismo le conste que Dios o su Profeta han dicho» 8 .

Frente al pluralismo interno del Islam, que supo integrar en su comunidad a diferentes sensibilidades religiosas, se alza la intransigencia dogmática del cristianismo medieval que convertía en "hereje", con las peligrosas consecuencias prácticas que de ello se derivaban, a todo creyente anticonformista. «Aunque pueda parecer paradójico, el hereje medieval no es nunca tal en sí, sino en la confrontación/conflicto con las instituciones del conformismo religioso. (...) $\mathrm{La}$ herejía medieval es, sobre todo, religiosidad crítica dentro de peculiares coordenadas históricas, y en la dialéctica con los hombres y las estructuras de la iglesia mayoritaria y dominante»?

Esa intransigencia religiosa llevaría a la jerarquía eclesiástica a intentar silenciar durante la Edad Media cualquier disidencia interna. Cuando el cristianismo hubo alcanzado la hegemonía social en Europa, puso en marcha una implacable represión contra tales disidentes, cuyo instrumento más eficaz sería, con el tiempo, la Inquisición. «Después de que el cristianismo se convirtiese en religión oficial del Imperio, los acontecimientos determinaron también la forma en la que la Iglesia medieval afrontó la herejía. Tras la conversión de Constantino, los cristianos tuvieron el poder efectivo del Estado y, pese a algunas indecisiones, lo usaron para imponer una uniformidad de creencias. Tanto en la parte oriental como en la occidental del imperio se ordenó que los herejes pertinaces fuesen objeto de pena de exilio, marca con hierro candente, confiscación de bienes o muerte. Tales disposiciones sobrevinieron a la caída del Imperio, así como la presunción del derecho de la Iglesia de recurrir al Estado para combatir la herejía” 10 .

\section{El pluralismo en al-Andalus}

¿Qué aportó la España musulmana a esta raíz común del pluralismo islámico? Fundamentalmente, una mayor acentuación de ese pluralismo (confirmado, como veremos más adelante, en el status jurídico reconocido a las comuni-

8 Miguel Asin Palacios, Abenházam de Córdoba y su bistoria critica de las ideas religiosas, Madrid, 1984, tomo IV, pp. 143-156, subrayado mío.

9 Grado Giovanni Merlo, Eretici ed eresie medievali, Bolonia, 1989, p. 19.

10 Malcolm D. LAMBERT, Le herejia medieval, Madrid, 1986, p. 17, subrayado mío. 
dades judía y cristiana), y el surgimiento de un racionalismo filosófico, con indudables elementos de modernidad, del que Averroes representa su mejor, pero no único, exponente. Esta doble contribución no puede ocultar, sin embargo, una realidad histórica: al-Andalus se distinguió entre los restantes pueblos islámicos por su vivo espíritu religioso. Recordemos aquella expresiva definición del último rey zīri 'Abd Allāh: ‘Al-Andalus, tanto en lo antiguo como en lo moderno, ha sido siempre un país de sabios, alfaquíes y gentes de religión».

Goldziher y otros estudiosos después de él desenfocaron, en mi opinión, la religiosidad y el poco arraigo de las sectas en la península, bajo el prejuicio ilustrado de que la "ortodoxia" era la otra cara del fanatismo. Pero ni la sociedad andalusí ni los sabios que de ella brotaron tan abundantemente se distinguieron por ese pretendido fanatismo, sino por todo lo contrario. Para argumentar mi punto de vista, me centraré en estos tres aspectos del mundo religioso de alAndalus: las sectas, la persecución de la heterodoxia y la receptividad ante las innovaciones.

\section{1. ${ }^{\circ}$ Las sectas}

Ibn Hazm nos informa en su Risäla fí fadl al-Andalus o Epistola sobre la excelencia de al-Andalus, parágrafo 32, de la escasez de teólogos y de la introducción del katam en la península a través precisamente de los mu tazilíes, los librepensadores del Islam, así como del escaso desarrollo de las sectas.

En un reciente estudio se ha rebatido el tópico de la "impermeabilidad" de al-Andalus al movimiento de las sectas, si bien el grupo étnico donde más arraigó fue entre los beréberes, por razones de carácter político y social ${ }^{11}$.

A la vista de las fuentes históricas, se impondría, por tanto, el reconocimiento del papel limitado de las sectas en la sociedad andalusí, pero sin negar por ello su penetración.

Mas esto no demuestra, en modo alguno, que allí imperara el fanatismo religioso, pues, como ya vimos, el Islam ofrece a los creyentes que siguen la senda común o sunna una capacidad de elección, un efectivo pluralismo interno, que para el cristianismo medieval, en su monolitismo dogmático, sólo podía

11 Cfr. Jorge AgUADE, "Some remarks about sectarian movements in al-Andalus", en Studia Islamica, LXIV, 1986, pp. 53-77. 
hallarse extramuros, es decir, en el ámbito prohibido de las sectas heréticas. ¿Habrá que recordar también que el miembro de una secta islámica sigue siendo musulmán en plenitud de derechos?

\section{La persecución de la heterodoxia}

Un panorama menos dramático del dibujado por algunos historiadores se deduce de una sólida investigación sobre el control ideológico en al-Andalus ${ }^{12}$. Los juristas mālikíes «se mostraron reticentes a la hora de recurrir a la acusación de zandaqa) (o sea, la herejía que implicaba responsabilidad penal ante los tribunales), dado que podría acarrear la imposición de la pena capital: «Esta cautela se aproxima bastante a la tolerancia». Durante los tres siglos de poder omeya, solamente hay noticia de seis acusaciones de zandaqa, de las cuales dos no dieron lugar a proceso judicial. En otras dos, se dictaron penas de muerte por considerar a los encausados peligrosos para la seguridad del Estado, algo que nada tiene que ver con la ortodoxia sino con el poder político, que era lo que en verdad preocupaba a los omeyas orientales y andalusíes, como ha subrayado B. Lewis. Ningún mu'tazilí llegó a ser procesado ${ }^{13}$.

\section{3. ${ }^{\circ}$ La receptividad a las innovaciones en al-Andalus}

Contamos con un texto de excepcional interés para rastrear este tema: la Introducción al arte de la Lógica escrita por el médico valenciano Ibn Tumlūs de Alcira (1165-1233). Su editor y traductor, don Miguel Asín, supo captar el valor historiográfico del prólogo de esta obra: «en él se traza a grandes rasgos el cuadro de las alteraciones que experimentó, a través de los siglos, el estrecho criterio teológico de los alfaquíes españoles, refractarios siempre a toda novedad científica, pero dispuestos también a aceptarla como ortodoxa, cuando en el transcurso del tiempo se habituaban a considerarla como cosa tradicional» 14 .

12 M.a Isabel FIERRo BELLO, La heterodoxia en al-Andalus durante el periodo omeya, Madrid, 1987.

13 Ibid., pp. 174-176.

14 IBN TUMLUS, Introducción al arte de la Lógica, Madrid, 1916, p. X, Prólogo del traductor. 
Ibn Tumlús comienza estudiando la evolución de las ideas en el campo del fiqh o derecho islámico. La primera escuela jurídica fue la awzā'í. Posteriormente, se propagó la mālikí, que acabaría imponiéndose. A raíz de los viajes a Oriente, se introdujeron en la España islámica libros de hadit o tradiciones, y nuevas doctrinas jurídicas. Ello provocó la reacción de los alfaquíes que estuvo a punto de costarle la vida a Baqi ibn Majlad, de no haber intervenido a su favor el emir. Pero también las doctrinas de Baqī, introductor del šáfi ismo, llegaron a ser asimiladas. "Así, al cabo de largo tiempo, acabaron por habituarse a aquello mismo que antes consideraban reprobable, $y$ se convirtió en dogma de fe, propio de la religión verdadera, lo que habia sido infidelidad y ateismon 15.

En el campo teológico ocurrió algo semejante. Los aš’ăries fueron acusados de infieles al principio. Al llegar a la península los libros de al-Gazzālī «hirieron los oídos de los alfaquíes porque contenían cosas a que no estaban acostumbrados, cosas que ni siquiera conocían...; presentáronse de común acuerdo ante el emir de entonces y le aconsejaron diese orden de que fueran quemados dichos libros». Gracias a la protección del Mahdī Ibn Tưmart, también los libros de al-Gazzāii terminaron atrayendo a los andalusíes. Se confirmaba una vez más la regla histórica apuntada por Ibn Tumlús: «Rechazar primero aquellas mismas doctrinas que al fin acababan por aceptar como buenas» 16.

De la síntesis de Ibn Tumlús se deduce el conservadurismo de los alfaquíes. No puede negarse, sin embargo, el hecho fundamental de que, como reconoce él mismo, todas las innovaciones teológico-jurídicas acabaron por ser difundidas y asimiladas en la Espańa musulmana, después de una resistencia inicial de los círculos conservadores ya mencionados. Añadamos por nuestra parte que el más prestigioso representante de la escuela jurídica zāhirī en todo el mundo islámico, y crítico implacable de la escuela mālikí, hegemónica en al-Andalus, fue el cordobés Ibn Hazm. Todo ello demuestra que el pueblo y el poder político fueron en al-Andalus más receptivos a las nuevas ideas de lo que algunos eruditos suelen admitir, y que el cacareado fanatismo brilló por su ausencia en el Islam peninsular.

15 Ibid., p. 14, subrayado mío.

16 Ibid., pp. 16 y 19. 
La tolerancia del Islam español

Una segunda raíz, derivada evidentemente de la primera, es la tolerancia del Islam español respecto a los creyentes de otras religiones. La convivencia pacífica de la religión hegemónica, el Islam, con las minorías cristiana y judía constituye un hecho excepcional en la Europa medieval.

La monarquía visigoda persiguió a los judíos; de ahí, la colaboración de éstos con las tropas musulmanas llegadas a la península. Con su política de tolerancia hacia los sefardíes el Islam español se aseguró el apoyo de este influyente grupo social urbano, especializado en el comercio. Por primera vez en Europa, los judíos salen del ghetto: la cultura medieval pronto empezaría a recoger los frutos de esa liberación política.

También se beneficiaron de esa tolerancia los cristianos, que pasaron a ser, junto con los judíos, "protegidos" o dimmies: a cambio de un impuesto, gozaban de autonomía interna, incluida la libertad religiosa, quedando libres de obligaciones militares. Los "pueblos del Libro" recibían así, en la práctica, un trato de favor derivado de su vinculación con la profecía de Mahoma. Cristianos y judíos, como nos recuerda Ribera, tenían en al-Andalus sus autoridades judiciales propias, al margen de la jurisdicción general islámica. Ibn Hazm, por ejemplo, se refiere en el Fisal (Primer tratado, capítulo 25) a "un cristiano, que era cadí de los cristianos de Córdoba y que venía a menudo a mi clase». El qädì-l-nasāāă, o juez de los mozárabes, aplicaba el derecho visigótico del Liber Iudiciorum, llamado más tarde Fuero Juzgo.

En un estudio que hizo época (El cancionero de Abencuzmán), don Julián Ribera demostró hace tiempo la pluralidad lingüística existente en al-Andalus, descubriendo el uso del romance no sólo en la vida popular sino incluso en las más altas esferas oficiales.

Éste es el cuadro general que ofrece Ribera:

1. “En la España musulmana coexistieron dos lenguas literarias: el árabe clásico y el latín clásico, y dos lenguas vulgares: el árabe vulgar y el latín vulgar o romance.

2. El latín clásico se mantuvo como lengua religiosa (y en algunas épocas y lugares como lengua literaria) por los cristianos que permanecieron en Andalucía durante la dominación musulmana, especialmente por el clero, que tenía que instruirse en la lengua ritual. 
3. El árabe clásico, como lengua literaria, no fue ya exclusiva de musulmanes, sino que se sirvieron de ella los cristianos andaluces. De esto se quejaba amargamente Alvaro de Córdoba...

4. ${ }^{\circ}$ El árabe vulgar y el latín vulgar fueron dos lenguas usadas indistintamente por las mismas personas, no sólo por los cristianos de la España musulmana, sino también por los musulmanes andaluces» 17.

Debemos añadir al cuadro anterior una referencia a la situación lingüística de los judíos andalusíes: hablaban hebreo en el ámbito familiar-religioso, y usaban el árabe literario como lengua culta o científica, sin dejar por ello de comunicarse en romance en la vida diaria, como lo demuestra todavía el ladino. ¡No es de extrañar que estos sefardíes dieran, con el tiempo, tan buenos traductores! Gracias a la protección de los omeyas, la lengua hebrea experimentó en al-Andalus un verdadero renacimiento. Como señaló el hebreísta don David Gonzalo Maeso, el ciclo hispano-árabe, que abarca más de quinientos años, "ha sido el más glorioso de toda la literatura hebrea postbíblica» ${ }^{18}$.

En cuanto al romance, era hablado en el medio familiar pero también en plazas y mercados de al-Andalus. Con él se ponían motes a personalidades de la vida pública. Llegó a introducirse en la lengua literaria, como lo demuestra la poesía de Ibn Quzmān. Y se utilizaba a veces en declaraciones ante los tribunales, e incluso en presencia del soberano omeya, según cuenta alJušānī en su Historia de los jueces de Córdoba. A juzgar por el testimonio de Ibn Hazm en su Yambarat ansäb al- arab, el romance debió ser conocido por la inmensa mayoría de los andalusíes de origen árabe, pues narra como algo insólito que vivía cerca de Córdoba una familia árabe tan apegada a sus tradiciones que "conservaba su lengua primitiva: no sabían hablar romance; únicamente sabían hablar árabe, no sólo los hombres sino también las mujeres”.

Símbolo de la tolerancia del Islam español es el califa 'Abd al-Rahmān III en cuyo reinado, en pleno siglo X, pacificada por fin la tierra de al-Andalus, fue nombrado ministro el médico judío Hasdāy ibn S̆aprūt, y embajador, el obispo cristiano de Córdoba. "Este hombre delicado y sagaz que centraliza, que funda la unidad de la nación y la del poder, que con sus alianzas establece una especie de equilibrio político y que con amplia tolerancia llama a sus consejos

17 Julián Rubera y TaRrago, Disertaciones y opúsculos, Madrid, 1928, tomo I, pp. 28-29.

18 "Los árabes, maestros de los judíos en la España medieval", en Ensayos sobre la filosofia en al-Andalus, cit., p. 168. 
a hombres de otra religión, es más bien un rey de los tiempos modernos que un califa de la Edad Media» ${ }^{19}$.

Las costumbres populares impregnaron de su falta de rigidez hasta a personalidades distinguidas por su ortodoxia. Por ejemplo, Almanzor, "columna de religión", instituyó el domingo como día de descanso para todos sus soldados, y bebió vino toda su vida, a excepción de los últimos años, según informa alMaqqarī.

El espíritu tolerante del pueblo andalusí queda bien reflejado en este pensamiento de uno de sus más brillantes intelectuales del siglo XI, Ibn Hazm de Córdoba: «Fíate del hombre religioso aunque profese religión distinta de la tuya, y jamás te fíes del hombre ligero y descreído aunque parezca profesar tu propia religión» 20 .

\section{El mestizaje en al-Andalus}

La tercera raíz de la que brotó el pensamiento filosófico andalusí es el mestizaje racial. En efecto, la formación misma de al-Andalus se basó en un original mosaico de razas.

A lo largo del siglo VIII se instalaron en la Península ibérica aproximadamente 50.000 árabes y unos 200.000 beréberes, si bien esta última cifra es menos segura. La principal novedad, ya desde el momento inicial de la conquista, reside en que la expansión del Islam no recae fundamentalmente en el pueblo árabe sino en las tribus beréberes del Magreb, recién islamizadas y no sin dificultad.

El hecho central desde el punto de vista de la población es, sin embargo, el siguiente: la abrumadora mayoría de los habitantes de al-Andalus, conversos o no, muladíes o mozárabes, eran de origen hispano-romano, y al cabo de varias generaciones de mezcla racial (no olvidemos que gran parte de las tropas musulmanas llegaron a la península sin sus mujeres), los diversos elementos exógenos acabaron fundiéndose en el crisol hispano.

Este mestizaje demostró en la práctica su eficacia cultural, como ya advirtió Averroes en su Comentario a los 'Meteorológicos' con un punto de orgullo an-

19 R. Dozy, Historia de los musulmanes de España, Madrid, 1984, tomo III, p. 88.

20 Los caracteres y la conducta, traducción de Miguel Asín, Madrid, 1916, parágrafo 79. 
daluz: «Esto es lo que ha sucedido en la tierra de al-Andalus con los descendientes de los árabes y beréberes, que la naturaleza [tras la mezcla de sangre] los ha igualado con los naturales de aquella tierra y por esto se han multiplicado entre ellos las ciencias".

Los historiadores han solido ver en la época de esplendor del califato el paradigma de integración racial en al-Andalus. $\mathrm{R}$. Dozy juzgó como uno de los grandes logros políticos de 'Abd al-Rahmān III al-Nāsir «la fusión de todas las razas de la península en una nación verdaderamente una» 21 .

Ibn Jaldūn, crítico siempre de la civilización urbana, reconoce en la $\mathbf{M u}$ qaddima (libro IV, capítulo $7 .^{\circ}$ ) que en al-Andalus se daba poca importancia a la genealogia, que no se procuraba conservar la pureza de sangre y no se hacía mucho caso al linaje de familia, todo lo cual llevaba a una debilitación de la fuerza de cohesión tribal o 'asabiyya.

Pero el modo de vida de los pueblos nómadas del desierto no podía tomarse seriamente como alternativa social para un país, como al-Andalus, de tan avanzada estructura urbana. Por ello, el nuevo Estado islámico, innovador en tantos aspectos de la vida medieval, se asentó sobre una población de variadísimo origen étnico (hispano-romanos, beréberes, árabes, judíos, eslavos o esclavones y hasta negros del Sudán) que acabaría mezclándose a través de un mestizaje racial cuya amplitud debió sorprender por igual a un viajero oriental que a un cristiano centroeuropeo.

\section{La filosofía de al-Andalus, fruto de aquel original mundo histórico}

Después de haber explorado las raíces del mundo intelectual de al-Andalus, se comprenderá mejor que aquel Renacimiento no fue un fenómeno milagroso, ni fruto del azar histórico. De la riqueza y novedad del pensamiento andalusí estuvo bebiendo la cultura europea durante varios siglos. Incluso hoy, algunos pensadores islámicos encuentran inspiración para el futuro en las ideas de aquellos audaces andalusíes, especialmente Averroes. Y el pensamiento judío sigue mirando a Maimónides como obligado punto de referencia.

Con sus principales filósofos musulmanes (Ibn Hazm, Ibn Bāŷy̆a, Ibn Tufayl e Ibn Rušd, el Averroes de los latinos) al-Andalus logró alcanzar al más de-

21 Historia de los musulmanes de España, tomo II, p. 276. 
sarrollado Islam oriental. Por vez primera, los grandes maestros orientales eran continuados, y hasta superados, por sus lejanos herederos intelectuales de la España musulmana.

Para un historiador tan competente como Ibn Jaldūn la gloria filosófica estaba compartida en el Islam. "Los que descollaron entre los musulmanes en esos estudios [de filosofía] fueron Abū Nasr al-Fārābĩ y Abū 'Alī Ibn Sinnā, ambos nativos del Islam oriental, y el cadí Abū-l-Walĩd ibn Rušd [Averroes] y el visir Abū Bakr ibn al-Sāig [Ibn Bāŷya, el Avempace de los escolásticos], oriundos de al-Andalus. Sin mencionar a otros. Esos hombres alcanzaron la máxima meta en el conocimiento de las ciencias racionales y adquirieron una gran reputación» 22 .

Otro fruto maduro del tolerante mundo andalusí fueron sus filosofos judíos que, libres de la represión visigoda y en contacto con la refinada cultura árabe-islámica, ocuparon un lugar de honor en el pensamiento medieval. De Ibn Gabirol a Maimónides, la comunidad sefardí imprimió un sello propio a su obra especulativa, escrita en árabe. Mientras tanto, en la Europa cristiana el aislamiento del ghetto mantenía a los judíos en la esterilidad filosófica.

Por más de un motivo, el desarrollo de la sociedad andalusí, y en particular su mundo intelectual, permite vislumbrar los albores de la modernidad. Mucho antes de que Ibn Tufayl afirmara la superioridad de la religiosidad interior sobre la religión tradicional, y cuando aún faltaba un siglo para que Averroes elaborara su racionalismo filosófico mediante la recuperación de un Aristóteles integral, el cordobés Ibn Hazm nos transmitía el plan de estudios de la "escuela filosófica" andalusí. Veamos cuál era su ratio studiorum. "Consagran las primicias de su inteligencia a las matemáticas e inauguran su formación científica por el estudio profundo de las propiedades de los números. Pasan luego gradualmente a estudiar la posición de los astros, la forma aparente de las esferas celestes, el modo de verificarse el paso del sol, de la luna y de los cinco planetas, la intersección de las esferas del sol y de la luna, la naturaleza de los cuerpos celestes, de las estrellas fijas, sus intervalos, su distancia de la tierra, sus volúmenes y todos los demás fenómenos y accidentes físicos y atmosféricos. Añaden a esto la lectura de algunos libros de los griegos en que se determinan las leyes que regulan el razonamiento discursivo, y también mezclan con esto el estudio de algunas teorías de los filósofos acerca de la astrología judiciaria...”23. Ibn

22 Muqaddima, traducción de Juan Feres, México D. F., 1977, libro VI, capítulo 13:

23 Fisal, traducción de Miguel Asín Palacios, Primer tratado, capítulo 22. 
Hazm captó bien el laicismo que inspira tal plan de estudios, más propio de una Facultad de Ciencias en una Universidad moderna que de un Estudio General medieval o de una madrasa oriental.

En resumen, la vida social de al-Andalus es el camino más seguro para comprender cómo pudo germinar en la Península ibérica la filosofía durante la Edad Media. Pienso que el pluralismo interno del Islam, acentuado en suelo peninsular, la tolerancia y el mestizaje racial de la España musulmana constituyen las firmes raíces de las que brotó con tanto vigor aquella singular filosofía.

Bajo el asedio militar de los reinos cristianos del Norte y la presión creciente de las tribus beréberes del Sur, desapareció aquel mundo histórico que llamamos al-Andalus. Pero a sus filósofos, musulmanes y judíos, podemos aplicarles hoy con toda justicia los versos de un poeta árabe:

"Ornamento de esta tierra fueron, en vida;

después de la muerte, son ornamento

de los libros y de la historia." 